\title{
Georisks and Sustainability Resource of The Mascarene Islands Territories to External Impacts
}

\author{
Viacheslav Iegupov ${ }^{1}$, Rajeshwar Goodary ${ }^{2}$, Yeshvin Goodary ${ }^{3}$ \\ ${ }^{1}$ Kharkiv National University of Civil Engineering and Architecture \\ 40 Sumska Street, 61002, Kharkiv, Ukraine \\ slavaegu@gmail.com \\ ${ }^{2}$ Université des Mascareignes \\ Avenue de la Concorde, Roches Brunes, Rose Hill, Mauritius \\ rgoodary@udm.ac.mu \\ ${ }^{3}$ McGill University, 845 Sherbrooke St W, Montreal, Quebec H3A 0G4, Canada \\ yeshvin.goodary@mail.mcgill.ca
}

\begin{abstract}
One of the most important tasks in making strategic decisions on the development of a particular region is objective information about geo-risks - natural or man-caused processes and phenomena that can cause damage to life, human health, or significant material losses. A reliable assessment of geo-risks, as well as the possibility of multi-risks, can be performed only by considering all the major impacts on existing natural and technogenic systems of urbanized territories and infrastructure facilities. At the same time, it is necessary to evaluate the ability of these systems to withstand external influences - a resource of sustainability. Geo-risks and the resource of resistance to external influences from a geotechnical and geological point of view were performed for the territories of the Mascarene Islands, which have both volcanic origin and predominantly biogenic. The advantage of the proposed approach is the unification of the principles of assessment, the need to take into account the capabilities of the natural resource and regulate its increase through preventive measures.
\end{abstract}

Keywords: georisks, external impacts, sustainability resource, volcanic islands, atolls

\section{Introduction}

An analysis of the risks of natural hazards (georisks) occurring in a particular region is an important element in land use planning, as well as for the implementation of the region's sustainable development strategy. The increase in the number of emergencies observed in recent years throughout the world requires taking into account both individual events and the interaction of various types of dangerous phenomena with each other. Often there is a "synergistic effect" that can occur with the simultaneous action of these events and it becomes necessary to study the nature of the trigger mechanisms leading to these effects. The combined consequences of such events often exceed by far the damage from each event individually. For example, a strong earthquake with subsequent mountain landslides and rock falls can cause the closure of mountain rivers, or vice versa, the destruction of natural dams or artificial hydraulic structures, with flooding in foothill areas.

Georisks assessment is one of the primary tasks of geo-ecological investigation in order to ensure life safety, especially for urbanized areas - complex natural-technical systems together with their regulatory measures, due to natural and technogenic factors. The basis for assessing georisk at the initial stage is to determine the types of geological hazards, their spatial distributions and intensities. Then, an analysis of the stability of the territories should be carried out in terms of the geological structure, geomorphology, geotechnical and hydrogeological conditions. Particular attention is required to areas with residential development and large existing and prospected infrastructure projects which are obviously the most vulnerable to negative geological processes.

The study of georisks together with the analysis of the safety of the human environment is necessary for the development and implementation of preventive measures and codes of practice with an aim to save lives in cases of natural disasters, such as earthquakes, volcanic eruptions, tsunamis, landslides, flash floods, the effects of climate change and others.

These problems are especially relevant for low- and middle-income countries, as these countries often face a high risk of death and casualties in natural disasters. This is often due to the lack of mandatory building codes - their poor quality or 
non-compliance, unsatisfactory urban planning, unauthorized community settlements and the lack of local technical management skills to handle high georisk disasters.

\section{Multi-risk assessment approach}

To solve these problems, the concept of "multi-risks" is currently being developed, including a group of more than one event that threatens a certain common region with an assessment of their interactions. This concept was first considered at the UN Conference on Sustainable Development in Rio de Janeiro [1] and then introduced into the Johannesburg Plan [2]. According to this concept, "multi-risk assessment should be understood as the process of determining the likelihood of various dangerous phenomena:

- occurring at the same time or soon after each other, since they depend on each other;

- or since they are caused by the same initiating event;

- or they threaten the same objects without a chronological coincidence."

To assess the ability to withstand negative environmental impacts, the concept of "sustainability resource of territories" $[3,4,5]$ may be used. This concept includes a set of indicators of external influences on the system and the levels at which this particular system functions within acceptable parameters. After a certain threshold value of the degree of influence, the system ceases to function in a normal, predetermined or acceptable mode.

The concept of "sustainability resource (or resistance) to external influences" (SR) is quite universal and can be applied to various natural and natural-technogenic systems. For example, in geotechnics, one of the indicators of SR is the allowable settlement of loess soil mass caused by the initial applied pressure, after which the soil structure is destroyed and irreparable damage occurs, due to excessive settlement. The value of such pressure allows characterizing weak soils during surveys for design and construction purposes. In hydrogeology: at a certain critical value of the SR territory for the infiltration of atmospheric precipitation or domestic/industrial water is the rise in the groundwater level to a critical threshold value, beyond which unacceptable flooding occurs.

Georisks during earthquakes are significantly less for areas with rocky foundations for buildings and structures that have a high stability resource, in contrast to sandy, especially water-saturated soil foundations spread on low atolls. Seismic effects on sandy water-saturated soils can cause a phenomenon such as liquefaction of soils, with the construction site plunging down causing their destruction. Such processes were observed in Indonesia and Japan [6]. On the other hand, in the mountainous areas of volcanic origin, multi-risks arise with a "synergistic effect" during seismic impacts due to soil collapses, rockfalls, landslides that are practically inexistent on low islands.

The damage from tsunami, as well as from global sea-level rise, will be greatest for islands and coral atolls with low absolute elevations (low SR), in contrast to high volcanic islands.

This paper aims to investigate and assess the georisks factors and sustainability resource for territories of the Mascarene Islands, located in the southern part of the Indian Ocean. The largest islands are Reunion with an area of $2512 \mathrm{~km}^{2}$, Mauritius - $1865 \mathrm{~km}^{2}$, Rodrigues $-104 \mathrm{~km}^{2}$. There are also many small islands and atolls - Agalega, St. Brandon, and others.

The large islands are of volcanic origin and consist mainly of basaltic deposits of varying degrees of weathering. Among these islands, the island of Mauritius is the oldest with an ascension period of the island in the range of $6.7-10$ million years. The islands of Reunion and Rodrigues were formed about 2 million years ago.

Mauritius was formed by the volcanic activities of the tectonic fault N100 [7] along a crack periodically erupting basaltic lavas and other volcanic products. The last phase of volcanic activity on the island is between 700,000 and 25,000 years. Lava emissions occurred from 26 craters located along the NNE-SSW axis, that is, parallel to the fault, which is currently off the island. This fact, as well as the absence of volcanism over the past 25 thousand years, may indicate a displacement of the upper part of the earth's crust along with the island away from the active fault. The remains of volcanic cones are the highest mountains on the island. The highest is Mount Piton de la Rivière Noire, $826 \mathrm{~m}$ high. No significant earthquakes were observed on the island (Fig. 1).

Reunion island is characterized by modern intensive volcanic activity. The active volcano Piton de la Fournaise, located in the southeast of the island, is one of the most active in the world (Fig 2a). There are also a number of volcanoes that are considered extinct. The highest of them, Piton des Neiges, has a height of $3069 \mathrm{~m}$. Seismic activity is associated 
with volcanic activity. On 10 February, 2020, within twenty minutes in the bowels near the volcano, Piton de la Furnes, seismographs recorded more than two hundred volcanic earthquakes.

Rodrigues Island is located in the so-called "triple junction point", where global mid-ocean ridges divide the bottom of of the Indian Ocean into three sectors: African, Indo-Australian, and the Antarctic. Ridges are characterized by underwater underwater volcanism, seismicity, and the rift structure of the axial zone. In the region of Rodrigues island, the system of of ranges is divided northward into the Arabian-Indian ridge and southwest into the Central Indian Ridge. Despite the volcanic origin of the island of Rodrigues, the maximum height of its surface is only 398 meters above sea level. By the virtue of its location, seismic and volcanic activities are very likely on the island.
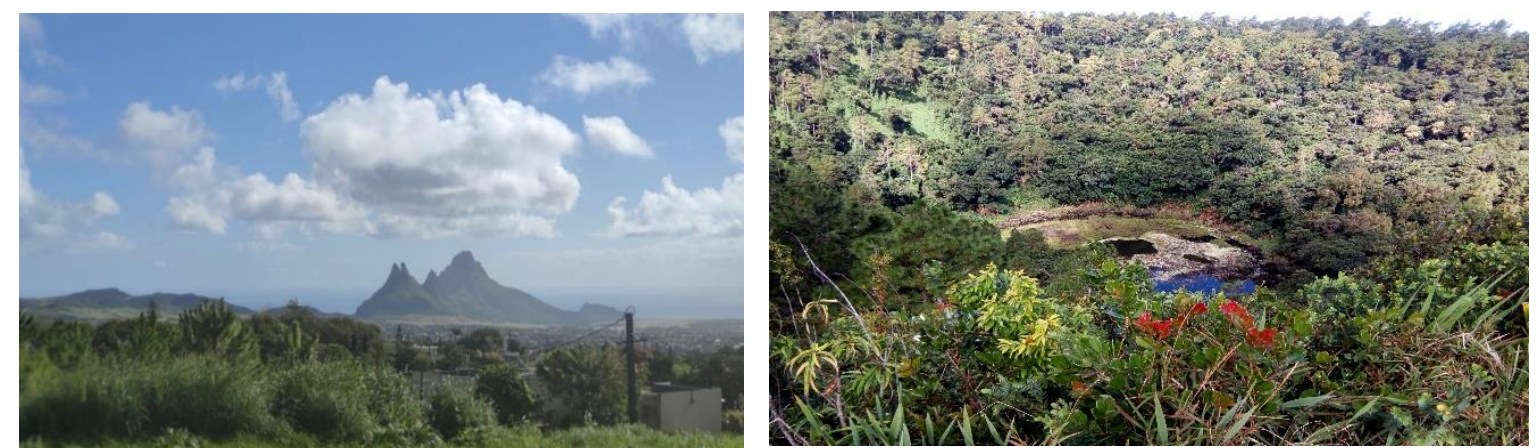

Fig. 1: Extinct volcano on the island of Mauritius

Agaléga atoll consists of two coral sand islands in the western part of the Indian Ocean (North and South), located 1100 $\mathrm{km}$ north of the island of Mauritius. The total area of the islands, separated by a small strait, is $24 \mathrm{~km}^{2}$. As in other tropical coral islands, soils are composed of bioclasts of calcareous organisms (material obtained from the skeletons of corals and many other animals and plants associated with corals) with an almost complete absence of silicon material. Beaches are developed all around and the wind accumulates lighter and thinner material in the dunes. Rainwater reach all this material, which, being almost completely made of calcium carbonate, is easily dissolved, and the dissolved lime re-precipitates around the bulk material, causing its cementation. The coastal dunes are located in the southeast of the South Island (Grande Montagne, rising to about 7 meters) and in the direction of the northeast of the North Island (Montagne d'Ernerez, rising to 15 meters). The interior of the beach and dunes is a very flat area, consisting of consolidated coral sand with a sandy surface and occasionally overlain by topsoil (Fig. 2b).

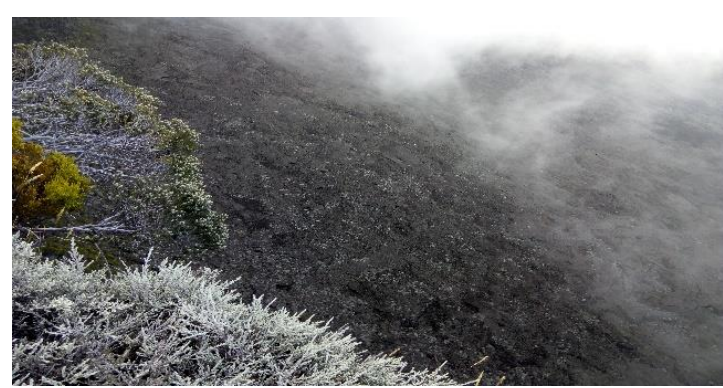

(a)

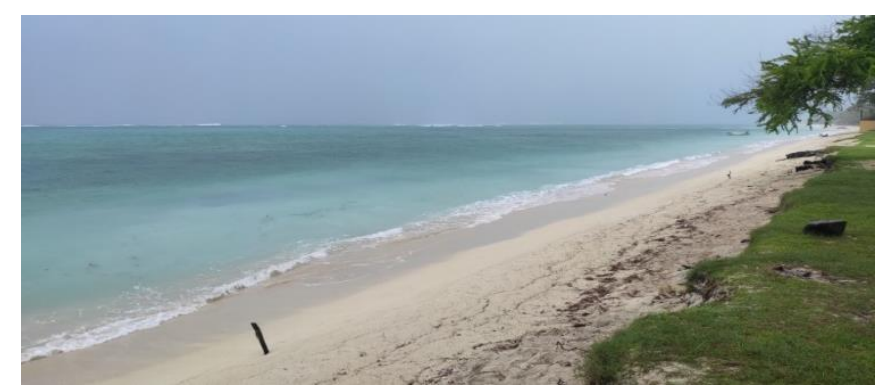

(b)

Fig.2: a - active volcano - Piton de La Fournaise, Reunion Island; $b$ - coral island beach

\section{Assessment of Georisks and Resource of Stability for the Mascarene Islands}

An assessment of the resource of stability of the territories of the Mascarene Islands to natural influences was performed from the geotechnical point of view of the development and consequences of the most significant hazardous engineering and geological processes, with a prior expert qualitative assessment. The analysis was done, based on published data and recent reported information on geological and geotechnical surveys in these territories [7,8]. When performing the assessment, 
georisks and sustainability resources were rated as 'high', 'medium', and 'low', depending on the gravity of the effects of their impact. The possibility of multi-risk occurrence has also been investigated and results of their evaluation are summarized in Table 1.

Table 1. Main Georisks and Sustainability Resource of the Mascarene Islands territories.

Legend: Georisk level: high, medium, low, possible, unlikely

\begin{tabular}{|c|c|c|c|c|}
\hline Georisks & Reunion & Mauritius & Rodrigues & Agalega and other coral islands \\
\hline Seismic impacts & High +++ & Low +++ & High +++ & Depends on location + \\
\hline Tsunami & Medium +++ & Medim +++ & High ++ & High+ \\
\hline Volcanic eruptions & High +++ & Low +++ & Medium +++ & Unlikely \\
\hline Landslides & Medium +++ & Medim +++ & Low +++ & Unlikely \\
\hline Rockfalls & High ++ & High ++ & Low ++ & Unlikely \\
\hline Mudflows & Medium ++ & Medium ++ & Low ++ & Unlikely \\
\hline Sea level rise & Possible +++ & Possible +++ & Possible ++ & Posible + \\
\hline
\end{tabular}

Sustainability resource: +++ - high, ++ - medium, + - low.

The* symbol indicates multi-risks:

*Earthquakes often cause landslides, rockfalls in the mountains; dilution of water-saturated soils and tsunamis.

**Volcanic eruptions are often accompanied by volcanic eruptions and mild earthquakes.

\section{Conclusion}

The advantage of the proposed approach is the unification of the principles of assessment, the need to take into account the capabilities of the natural resource and regulate its increase through preventive measures, which is the basis for building harmonious and safe human relations with the environment. Further research on the quantitative assessment of the degree of impact of the listed geo-risks on the territory, the development and implementation of necessary measures to protect against dangerous natural phenomena is deemed necessary for the Mascarene Islands territories.

\section{References}

[1] United Nations Conference on Environment \& Development /Rio de Janeiro, Brazil, 3 to 14 June 1992.AGENDA 21 Available: https://sustainabledevelopment.un.org/content/documents/Agenda21.pdf.

[2] UN. Johannesburg plan of implementation of the world summit on sustainable development // Tech. rep., United Nations, 2002. Available: http://www.un.org/esa/sustdev/documents/WSSD_POI_PD/English/WSSD_PlanImpl.pdf.

[3] G. G. Strizhelchik, "Problems of engineering geology of cities and possible ways to solve them". Engineering geology, no. 2, pp. 3-12, 1987 (in Russian).

[4] V. Iegupov and G. Strizhelchik, "Sustainability resource of the hydrogeosphere to anthropogenic impacts with urbanization" in Book of Abstracts of the Geoethics \& Groundwater Management Congress, Porto, Portugal, May 2020. P. 51.

[5] G. G. Strizhelchik, V. Yu. Iegupov., I. V. Khrapatova "Engineering Geology”. Kharkiv: Typography Madrid, 2017 (in Russian).

[6] SNI 8460:2017 Persyaratan Perancangan Geoteknik. Available: https://simantu.pu.go.id/epel/edok/25e9d_19_ASPEK_KEGEMPAAN_DALAM_PERANCANGAN_GEOTEKNIK JEMBATAN_-_ASRURIFAK.pdf.

[7] Proag, V. (1995), The geology and water resources of Mauritius, analysis, Mahatma Gandhi Institute.

[8] Goodary R. Soil Testing in Weathered Volcanic Basalt. Proceedings:Ninth All-Ukrainian scientific-technical conference "Soil mechanics, geotechnics and foundation engineering": October 3 - 7, 2016: 312-325. Dnipro, Ukraine. 